\title{
Spontaneous Live Twin Tubal Ectopic Pregnancy: A Case Report
}

\author{
R Benn, V Wheeler, C Keshi
}

\begin{abstract}
We report the case of a 29-year old $\mathrm{GBP}^{+1}$ woman with a spontaneously conceived live twin tubal ectopic pregnancy. Her history was significant for infertility for 11 years after an induced abortion. Pelvic ultrasound scan showed live twin ectopic pregnancy and a partial salpingectomy was done.
\end{abstract}

Keywords: Ectopic pregnancy, live twin, tubal pregnancy, twin pregnancy, unruptured

WIMJ Open 2016; 3 (1): 25

\section{INTRODUCTION}

Unilateral twin tubal ectopic pregnancies are rare forms of ectopic pregnancies, with an incidence of 1 in 200 ectopic pregnancies (1). First described by DeOtt in 1891, there are just over 100 published cases in the literature, about 10 of which were diagnosed preoperatively. Gualandi et al reported the first case of live twin ectopic pregnancy in 1994 (2). This case report is of a patient with a live twin tubal ectopic pregnancy who was managed at the Scarborough General Hospital.

\section{CASE REPORT}

A 29-year old woman, gravida 3 para 1 abortus 1 at $6^{+3}$ weeks gestational age was referred to the Scarborough General Hospital. She experienced two episodes of per vaginal spotting that resolved. There were no symptoms of anaemia and no abdominal pain. She had a vaginal delivery 12 years prior, an induced abortion a year after that, and subsequent infertility due to tubal obstruction. She has regular menses, no known history of sexually transmitted infections, and was not under any fertility treatment.

On examination, her vital signs were blood pressure $110 / 67 \mathrm{mmHg}$ and pulse 95 per minute. Her mucous membranes were pink and moist, abdomen was benign, and pelvic examination revealed no bleeding, no adnexal masses, normal size anteverted uterus, and no cervical excitation tenderness. A urine pregnancy test was positive; haemoglobin was $13.7 \mathrm{~g} / \mathrm{dL}$ and haematocrit $35.9 \%$. Beta-human chorionic gonadotropin ( $\beta$-hCG) was not done. A transvaginal ultrasound revealed an anteverted uterus with no

From: Department of Obstetrics and Gynaecology, Scarborough General Hospital, Trinidad and Tobago.

Correspondence: Dr R Benn, Department of Obstetrics and Gynaecology, Scarborough General Hospital, Connector Road, Signal Hill, Tobago,

Trinidad and Tobago. E-mail: rondell_benn@yahoo.com intrauterine pregnancy, normal ovaries and two gestational sacs $(29 \times 21 \mathrm{~mm}$ and $36 \times 20 \mathrm{~mm})$ at the left adnexa and no free fluid (Fig. 1). Each gestational sac demonstrated an embryo (crown-rump-length $10 \mathrm{~mm}[7+1$ weeks] and 11 $\mathrm{mm}[7+2$ weeks $]$ ) with cardiac activity. A diagnosis of left adnexal live unruptured twin ectopic pregnancy was made and the patient agreed to salpingectomy.

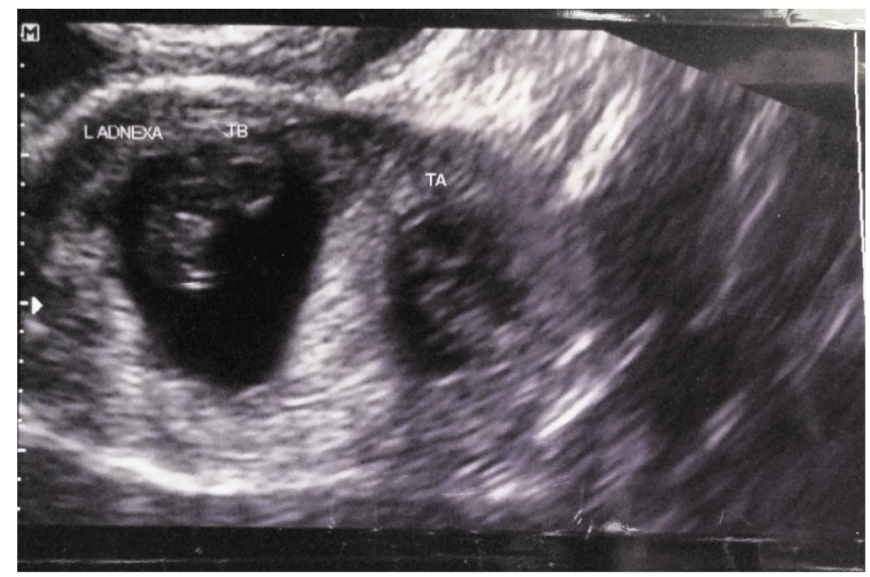

Fig. 1: Ultrasound image with two gestational sacs in the left adnexa, each with embryo: twin A (TA) and twin B (TB).

At laparotomy, an unruptured twin ectopic pregnancy was identified in the left fallopian tube (Fig. 2), and a partial left salpingectomy done. Her uterus, ovaries and right fallopian tube appeared to be normal. There were no intraoperative complications and blood loss was $<100 \mathrm{~mL}$. Her postoperative care was without incident and she was discharged the day after surgery. On review three weeks later, she remained well and histopathology confirmed the established diagnosis. 


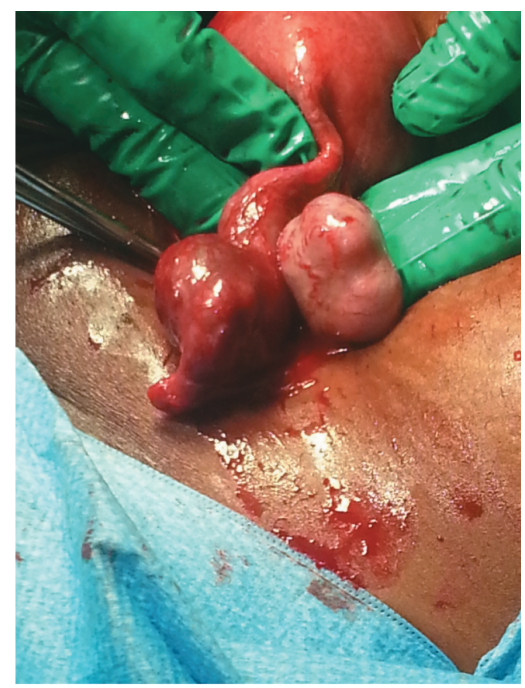

Fig. 2: Left fallopian tube with two swellings (twin ectopic pregnancies) and left ovary at surgery.

\section{DISCUSSION}

Ectopic pregnancy is an uncommon gynaecologic condition with variable presentations and accounts for $1-2 \%$ of pregnancies (3). Though tuboplasty and assisted reproductive technology have resulted in increased rates, sexually transmitted infections remain the most important risk factor. Still, many patients with ectopic pregnancy have no identifiable risk factors. It is also suggested that the larger cell mass of the fertilized twin zygote may result in retarded tubal transport with consequential tubal implantation. In our patient, there was a history of an induced abortion, difficulty conceiving and obstructed fallopian tubes, probably as a consequence of undiagnosed pelvic infection after the abortion. She had no risks for twin pregnancy.

In the United Kingdom and United States of America, ectopic pregnancy is the leading cause of first trimester pregnancy-related maternal deaths (4). In developing countries, $10 \%$ of women diagnosed with ectopic pregnancy in hospitals ultimately die (5). In Trinidad and Tobago, the incidence is unknown and there was only one published study. Data from 10 hospitals in Trinidad reported an incidence of 9.02 per 1000 patients and a maternal mortality rate of $1.3 \%(6)$. In that study, there was one twin ectopic pregnancy among 153 patients.

Ectopic pregnancy remains a diagnostic challenge due to its varied clinical presentation and can result in significant morbidity and mortality. Transvaginal ultrasound is very effective in diagnosing an intrauterine pregnancy by 24 days post ovulation with $90 \%$ sensitivity, $99.8 \%$ specificity, $93 \%$ positive predictive value, and $99.8 \%$ negative predictive value (7). In our case, the patient had a transvaginal ultrasound in the seventh week of pregnancy which identified two live embryos at the left adnexa.

Given the size of the embryos and the presence of cardiac activity, surgical intervention was the preferred option. In the other reported cases of twin ectopic pregnancy, surgical management was also the preferred option. There were four cases where medical management with methotrexate was tried; each of those cases was with absent cardiac activity and in one case, methotrexate treatment failed $(1,8-$ 11).

With a history of blocked fallopian tubes, the benefits of salpingostomy compared to salpingectomy were questionable. A recently published randomized control trial by Mol et al reported higher risks of morbidity with salpingostomy such as repeat ectopic pregnancy [ $8 \%$ vs 5\%; RR 1.6], persistent trophoblast [7\% vs $<1 \%$, RR 15] and conversion to salpingectomy [20\%] (12). Mol et al failed to show an increased chance of subsequent intrauterine pregnancy with salpingostomy, and reported the cumulative ongoing pregnancy rate as $60.7 \%$ vs $56.2 \%$. In patients who underwent in vitro fertilization, the difference was insignificant. These findings are supported by a number of systemic reviews and are consistent with current guidelines that suggest salpingectomy as the surgery of choice, and that salpingostomy should only be considered if there is contralateral diseased tube (12-14). These issues were discussed with our patient before her admission and she consented for salpingectomy.

The patient's most likely cause of ectopic pregnancy was tubal damage secondary to undiagnosed pelvic infection. Given the timeline, it is reasonably possible that the infection resulted from the induced abortion 11 years ago. With the availability of in vitro fertilization, the patient has a chance at subsequent pregnancy.

\section{CONCLUSION}

This case of spontaneously conceived live twin ectopic pregnancy is a rare form of ectopic pregnancy and illustrates the risk of ectopic pregnancy in patients with a history of infertility. Even though it is rare, twin ectopic pregnancy should be considered in patients, especially in those with increased risk.

\section{AUTHORS' NOTE}

The authors declare no conflicts of interest. This manuscript was orally presented at the Trinidad and Tobago Medical Association's 21 ${ }^{\text {st }}$ Medical Research Conference, St Augustine, Trinidad and Tobago on July 5, 2015.

\section{REFERENCES}

1. Ghanbarzadeh N, Nadjafi-Semanani M, Nadjafi-Semanani A, NadjafiSemanani F, Shahabinejad S. Unilateral twin tubal ectopic pregnancy in a patient following tubal surgery. J Res Med Sci 2015; 20: 196-8.

2. Gualandi M, Steemers N, de Keyser JL. First reported case of preoperative ultrasonic diagnosis and laparoscopic treatment of unilateral, twin tubal pregnancy. Rev Fr Gynecol Obstet 1994; 89: 134-6.

3. Bouyer J, Coste J, Shojaei T, Pouly JL, Fernandez H, Gerbaud L et al. Risk factors for ectopic pregnancy: a comprehensive analysis based on a large case-control, population-based study in France. Am J Epidemiol 2003; 157: 185-94. 
4. Farquhar CM. Ectopic pregnancy. Lancet 2005; 366: 583-91.

5. Leke RJ, Goyaux N, Matsuda T, Thonneau PF. Ectopic pregnancy in Africa: a population-based study. Obstet Gynecol 2004; 103: 692-7.

6. Daisley H. Ectopic pregnancies in Trinidad. A clinic-pathological study of 154 consecutive surgically treated cases. West Indian Med J 1989; 38: $222-7$.

7. Condous G, Kirk E, Lu C, Van Huffel S, Gevaert O, De Moor B et al. Diagnostic accuracy of varying discriminatory zones for the prediction of ectopic pregnancy in women with a pregnancy of unknown location. Ultrasound Obstet Gynecol 2005; 26: 770-5.

8. Fernanzez H, Bourget P, Lelaidier C, Doumerc S, Frydman R Methotrexate treatment of unilateral twin ectopic pregnancy: case report and pharmacokinetic considerations. Ultrasound Obstet Gynecol 1993; 3: 357-9.

9. Arikan DC, Kiran G, Coskun A, Kostu B. Unilateral tubal twin ectopic pregnancy treated with single-dose methotrexate. Arch Gynecol Obstet 2011; 283: 397-9. doi: 10.1007/s00404-010-1449-6. Epub 2010 Apr 8.

10. Dilbaz S, Karadeniz RS, Ozkan SD. Unilateral twin tubal pregnancy successfully treated with methotrexate. Int J Gynaecol Obstet 2008; 102: 171.

11. Marcovici I, Scoccia B. Spontaneous bilateral tubal ectopic pregnancy and failed methotrexate therapy: a case report. Am J Obstet Gynecol 1997; 177: 1545-6.
12. Mol F, van Mello NM, Strandell A, Strandell K, Jurkovic D, Ross J et al. Salpingostomy versus salpingectomy in women with tubal pregnancy (ESEP study): an open label, multicentre, randomized controlled trial. Lancet 2014; 383: 1483-9. doi: 10.1016/S0140-6736(14)60123-9. Epub $2014 \mathrm{Feb} 3$.

13. Nama V, Manyonda I. Tubal ectopic pregnancy: diagnosis and management. Arch Gynecol Obstet 2009; 279: 443-53.

14. Kelly AJ, Sowter MC, Trinder J; on behalf of the Guidelines and Audit Committee of the Royal College of Obstetricians and Gynaecologists. The management of tubal pregnancy. Guideline No. 21. London, UK: RCOG Press; 2004 [reviewed 2010]. Available from: www.ranzcog. edu.au/doc/rcog-tubal-pregnancy.html

Received 13 Jul 2015

Accepted 10 Sep 2015

Published 08 Feb 2016

Online: http://www.mona.uwi.edu/wimjopen/article/1658

(C) Benn et al 2016.

This is an open access article made freely available under Creative Commons Attribution 4.0 International (CC BY 4.0). Users are free to share, copy and adapt this work as long as the copyright holder (author) is appropriately and correctly credited. See http://creativecommons.org/ licences/by/4.0/deed.en_us for more information. 